The Development of Critical Engineering Agency, Identity, and the Impact on Engineering Career Choices

Ms. Allison Godwin, Clemson University

Dr. Geoff Potvin, Clemson University

Prof. Zahra Hazari 


\title{
The Development of Critical Engineering Agency, Identity, and the Impact on Engineering Career Choices
}

\begin{abstract}
The choice of an engineering discipline upon entrance to college is often a partly informed decision. This paper explores the agency and identity of engineering students through the lens of critical engineering agency as a first step in the development of an affective model that describes the choice of engineering as a college major. The nationally representative Sustainability and Gender in Engineering (SaGE) survey was completed by 6,772 college students across the U.S. who were enrolled in first-year English courses during Fall 2011. The topics included in this survey covered students' experiences in their last high school science classes, beliefs about engineering and sustainability, as well as demographics and students' prior academic performance. Exploratory factor analyses were performed to identify measures of personal agency and global agency and validate the constructs of identity for use in a critical engineering agency model. These constructs were regressed on the choice of engineering and science. The results indicate that the combination of strong math and science identities paired with high personal agency can increase the likelihood of the choice of engineering. While students who pursue science and engineering have similar high school science experiences in terms of preparation before college, engineering students are distinguishable through their elevated math identities and personal agency over science students. These results indicate that preparation and recruitment of future engineers would be improved by focusing on the aspects of engineering which are relevant to students' sense of personal agency and incorporate math and science interests and experiences.
\end{abstract}

\section{Introduction}

In view of the current situation of the STEM education pipeline, the President's Council of Advisors in Science and Technology (PCAST) recently called for one million additional STEM graduates over the next ten years. ${ }^{1}$ One way to address the need for more STEM graduates is through understanding what causes students to choose engineering and how to more effectively recruit them upon entrance into college.

A potential way to begin to address this need for a greater pool of new engineering students is through the interpretive framework of critical engineering agency. This perspectives is rooted in critical science agency theory which has been developed in qualitative research in science education but has not been applied in (quantitative) engineering education research. Critical engineering agency has been adapted from the earlier framework of critical science agency used in physics classrooms by Basu and Barton. ${ }^{2-4}$ This framework is a synthesis of several other ideas that provides a relevant framework that weighs student motivation, identity, and empowerment in certain contexts. This paper is a first step in this adaptation of critical science agency to validate this new critical engineering agency framework.

In this case, agency refers to the capacity of an agent, a person or other entity, to act in the world. Agency can also be thought of as "a process of understanding the effects of oppression and leveraging resources to act against it."2 The "critical” aspect of critical engineering agency 
includes students becoming critics of science in general through critical thinking as well as being self-reflective critics of their own behaviors and beliefs. This theoretical framework specifically refers to a student's perception of their ability to change their world through everyday actions as well as his/her broader goals in life. Critical engineering agency involves an understanding of engineering and engineering related processes, the skills and modes of inquiry associated with engineering, self-identification as possessing certain degrees of expertise in one or more realms associated with engineering, and the use of engineering as a foundation for enacting change in the world. The development of critical engineering agency may subsequently lend to students' professional identity development, an advancement of their position in the world, and/or altering their world in ways they envision. ${ }^{5}$

Identity is the authoring of a self within a particular context. ${ }^{6}$ In this review the particular context is within the engineering discipline. The concept of identity is associated to an individual's responses at a particular moment in time and how these responses are stable and/or change over time. By understanding this authorship, statements about a student's agency can be drawn. The importance of understanding identity is highlighted by Brickhouse et al.: if more students are to enter science and engineering, they need to see themselves as the "kind of people who would want to understand the world scientifically."7

Like the call that Brickhouse et al. made a decade ago to increase work on science identity to understand STEM persistence and learning, a similar drive has motivated an increase in research on engineering identity ${ }^{8}$. In support, Matusovich et al. ${ }^{9}$ found that attainment value, which is related to engineering identity (being an engineer is consistent with sense of self), was important for the persistence of engineering students during their undergraduate programs, more important than interest or perceived utility. Other recent research on students' engineering identity has also focused on the college years examining both engineering and professional identity development. For example, Chachra et al. ${ }^{10}$ studied the development of engineering identity during the undergraduate years and found a substantial dependence on the culture of engineering schools as well as students' beliefs about what constitutes engineering practice (e.g. “technical” work versus other aspects). The importance of school culture for engineering identity development has also emerged in other work. ${ }^{11}$ Another theme of recent work has been on the role of professional identity development since students who aspire to be engineers have been found to have more distinct professional and occupation-related identities, even at a very early age. ${ }^{12,13}$ There are, however, few studies that focus on the effect of pre-college experiences ${ }^{12}$ although the importance of such experiences and early exposure to engineering has been stressed (Beam et al., 2009). ${ }^{14}$ In addition, much of the prior research has acknowledged the importance of considering a multiplicity of identities but little research has been conducted on the effect of other STEM disciplinary identities on the development of an engineering identity. Considering a multiplicity of identities is important since other identities will lend to and interact with the development of an engineering identity. Subsequently, a focus on interwoven identities and pre-cursor identities (those that precede engineering identity development because students have little early exposure to engineering) will help us better understand the students who gravitate towards engineering and those who are lost because of perceptions about engineering practices and performances which conflict with their other views of themselves (other identities). This work is a first step toward understanding the engineering identity that precedes choice of engineering as a major in college. 
The construct of identity used in this work is based on four measurable dimensions of students' beliefs about their performance, competence, recognition by others, and interest. ${ }^{15}$ These dimensions richly capture the formation of an identity and can be used to study the creation of an engineering identity specifically in relation to critical engineering agency. Previous work has found that the constructs of performance and competence are highly correlated and are measured as a single construct. ${ }^{16}$ Additionally, the study of identity has proven useful in understanding persistence in other STEM domains. ${ }^{17}$ This framework for measuring identity has been established through large scale studies in physics and mathematics. ${ }^{15,16}$ The recognition component consists of outside recognition by parents, teachers, other students, etc. of a person as a good engineering student. Interest in the subject material also plays a key role in choice of engineering as a major. Students should have some understanding the realm of engineering in order to be be attracted to engineering and, hence, have an opportunity to develop an identity and agency with respect to engineering.

This paper is a first step in the development and establishment of a measure for critical engineering agency that has predictive power for the choice of engineering as a college major and/or career. Understanding the particular identity or identities and agency that students who choose engineering have is especially important for increasing the number and diversity of engineers in the workforce. The unique approaches of and the problem-solving strategies used by engineers are essential in a growing globally competitive marketplace, the ongoing restructuring of industry, the increased use of technology, and the emphasis on new energy sources in the world.

\section{Methodology}

The data used in this study were drawn from the Sustainability and Gender in Engineering (SaGE) project (http://www.clemson.edu/ gpotvin/SaGE.pdf) which comprises is a large-scale study of students enrolled in introductory English courses at 2 and 4 year colleges across the U.S. (NSF GSE 1036617). These data are a nationally representative sample of college students enrolled in introductory English courses during the Fall semester of 2011. Drawing from a stratified random sample of colleges and universities across the U.S. taken from the National Center for Education Statistics (NCES), this study collected data from 6,772 students attending 50 different institutions. The SaGE survey included questions on students' career goals, high school science and math experiences, science enrollment and achievement (courses taken, grades, AP test scores, etc.), student attitudes about sustainability, science and engineering, and demographic information. The development of the SaGE survey was organized into three main components: 1) a literature review to identify factors that may influence increased enrollment in engineering, 2) an extraction of items from previous national studies (Factors Influencing College Science Success - FICSS, Persistence Research in Science \& Engineering - PRiSE, and Factors Influencing College Success in Mathematics - FICS-Math) and, 3) open-ended responses from 83 high school science teachers across the nation via a survey administered on-line.

The R programming language statistical software system was employed to to examine the identity and agency constructs and to build a regression model of choice of engineering as a major or career. ${ }^{18}$ First, an exploratory factor analysis was conducted to examine how well the items on the SaGE survey related to mathematics identity, physics identity, and general science 
identity loaded on the theorized sub-constructs. If the resulting factors aligned with the framework, then the data also support the construct validity of the sub-constructs in the framework of identity (interest, recognition, performance/competence). For physics identity, nine items loaded onto the three constructs as theorized. Ten factors were included in the analysis of mathematics identity and loaded onto the three identity factors. For general science identity, a total of twelve factors were used, but only two factors were assessed: interest and performance/competence. A promax (non-orthogonal) rotation was employed in each case since the theory naturally permits inter-correlation between the sub-constructs (i.e. the factors were not expected to be orthogonal). Next, another exploratory factor analysis was conducted to examine how well the questions theorized to measure agency and being critical loaded together. From the survey, twelve items loaded onto two separate agency factors (described below). Finally, the constructs of physics, mathematics, and science identity along with the two agency factors were regressed on the choice of engineering as a career (i.e. engineering career choice was set as an interval/ratio variable in a linear regression model), while controlling for the level of parents' education (a socio-economic indicator) and gender. The constructs for each of the different types of identity were created by averaging each of the sub-constructs measured by the factors in the exploratory factor analyses discussed previously. The choice of engineering was determined by utilizing a question that asked students to "Please rate the current likelihood of your choosing a career in the following:" for a variety of science, math, and engineering careers on a Likert-type scale. A student's strongest response to any of the several engineering disciplines was used as a proxy for a student's interest in pursuing a career in engineering. This method was used in order to capture students interested in engineering in general (but undecided on a discipline) as well as students with a very well-specified interest in one or two engineering disciplines. 


\section{Results}

The 9 items for physics identity aligned on the theorized sub-constructs with competence and performance items loading together. Thus, performance and competence were combined under Factor 1 . Factor loadings ranged from 0.546 to 0.943 indicating that, to a great extent, items accurately captured the same construct. The mean loading for the factors were as follows: 0.763 for performance/competence, 0.820 for recognition, and 0.686 for interest. For all exploratory factor analyses conducted, the cut off for factor loadings was set at 0.4 . Any factors loading at values less than 0.4 are not a reliable measures for the sub-construct and were not included in this analysis.

Table 1: EFA of Physics Identity

\begin{tabular}{|l|c|c|c|c|}
\hline \multicolumn{1}{|c|}{ Statement } & $\begin{array}{c}\text { Factor 1 - } \\
\text { Performance/ } \\
\text { Competence }\end{array}$ & $\begin{array}{c}\text { Factor 2- } \\
\text { Recognition }\end{array}$ & $\begin{array}{c}\text { Factor 3 - } \\
\text { Interest }\end{array}$ & Uniqueness \\
\hline $\begin{array}{l}\text { Q27 Phys_b: my } \\
\text { parents/relatives/friends see me as a } \\
\text { physics person }\end{array}$ & & 0.743 & & 0.237 \\
\hline $\begin{array}{l}\text { Q27 Phys_c: my physics teacher sees } \\
\text { me as a physics person }\end{array}$ & & 0.898 & & 0.128 \\
\hline $\begin{array}{l}\text { Q27Phys_d: I am interested in } \\
\text { learning more about this subject }\end{array}$ & & & 0.825 & 0.149 \\
\hline $\begin{array}{l}\text { Q27Phys_f: I am confident that I can } \\
\text { understand this subject outside of } \\
\text { class }\end{array}$ & & & & \\
\hline $\begin{array}{l}\text { Q27Phys_g: I enjoy learning the } \\
\text { subject }\end{array}$ & & & & 0.234 \\
\hline $\begin{array}{l}\text { Q27Phys_h: I can do well on exams } \\
\text { in this subject }\end{array}$ & 0.943 & & & 0.187 \\
\hline $\begin{array}{l}\text { Q27Phys_i: I understand concepts I } \\
\text { have studied in this subject }\end{array}$ & 0.901 & & & 0.147 \\
\hline $\begin{array}{l}\text { Q27Phys_j: others ask me for help in } \\
\text { this subject }\end{array}$ & 0.602 & & & 0.126 \\
\hline $\begin{array}{l}\text { Q27Phys_n: I can overcome setbacks } \\
\text { in this subject }\end{array}$ & 0.740 & & & 0.480 \\
\hline
\end{tabular}


The 10 items for mathematics identity also aligned on the theorized sub-constructs with competence and performance items loading together. Thus, performance and competence were combined under Factor 1 . Factor loadings ranged from 0.486 to 0.979 . The mean loading for the factors were as follows: 0.812 for performance/competence, 0.863 for recognition, and 0.732 for interest.

Table 2: EFA of Mathematics Identity

\begin{tabular}{|c|c|c|c|c|}
\hline Statement & $\begin{array}{l}\text { Factor } 1- \\
\text { Performance/ } \\
\text { Competence }\end{array}$ & $\begin{array}{c}\text { Factor 2- } \\
\text { Recognition }\end{array}$ & $\begin{array}{c}\text { Factor } 3 \text { - } \\
\text { Interest }\end{array}$ & Uniqueness \\
\hline $\begin{array}{l}\text { Q27Math_b: my } \\
\text { parents/relatives/friends see me as a } \\
\text { math person }\end{array}$ & & 0.904 & & 0.157 \\
\hline $\begin{array}{l}\text { Q27Math_c: my physics teacher sees } \\
\text { me as a math person }\end{array}$ & & 0.823 & & 0.169 \\
\hline $\begin{array}{l}\text { Q27Math_d: I am interested in } \\
\text { learning more about this subject }\end{array}$ & & & 0.979 & 0.005 \\
\hline $\begin{array}{l}\text { Q27Math_e: I am confident that I can } \\
\text { understand this subject in class }\end{array}$ & 0.829 & & & 0.176 \\
\hline $\begin{array}{l}\text { Q27Math_f: I am confident that I can } \\
\text { understand this subject outside of } \\
\text { class }\end{array}$ & 0.756 & & & 0.219 \\
\hline $\begin{array}{l}\text { Q27Math_g: I enjoy learning the } \\
\text { subject }\end{array}$ & & & 0.486 & 0.254 \\
\hline $\begin{array}{l}\text { Q27Math_h: I can do well on exams } \\
\text { in this subject }\end{array}$ & 0.932 & & & 0.166 \\
\hline $\begin{array}{l}\text { Q27Math_i: I understand concepts I } \\
\text { have studied in this subject }\end{array}$ & 0.948 & & & 0.148 \\
\hline $\begin{array}{l}\text { Q27Math_j: others ask me for help in } \\
\text { this subject }\end{array}$ & 0.637 & & & 0.312 \\
\hline $\begin{array}{l}\text { Q27Math_n: I can overcome setbacks } \\
\text { in this subject }\end{array}$ & 0.768 & & & 0.486 \\
\hline
\end{tabular}


The 12 items for general science identity aligned on the theorized sub-constructs with competence and performance items again loading under the same factor. Factor loadings ranged from 0.660 to 0.904 . The items theorized to measure general science recognition did not hold together in the factor analysis and were subsequently removed from the analysis. The mean loading for the factors were as follows: 0.791 for performance/competence and 0.795 for interest.

Table 3: EFA of General Science Identity

\begin{tabular}{|l|c|c|c|}
\hline \multicolumn{1}{|c|}{ Statement } & $\begin{array}{c}\text { Factor 1 - } \\
\text { Interest }\end{array}$ & $\begin{array}{c}\text { Factor 2- } \\
\text { Performance/ } \\
\text { Competence }\end{array}$ & Uniqueness \\
\hline $\begin{array}{l}\text { Q25a: interest in understanding natural } \\
\text { phenomena }\end{array}$ & 0.660 & & 0.547 \\
\hline $\begin{array}{l}\text { Q25b: interest in understanding science in } \\
\text { everyday life }\end{array}$ & 0.835 & & 0.283 \\
\hline $\begin{array}{l}\text { Q25c: interest in explaining things with } \\
\text { facts }\end{array}$ & 0.691 & & 0.513 \\
\hline $\begin{array}{l}\text { Q25d: interest in telling others about } \\
\text { science concepts }\end{array}$ & 0.904 & & 0.210 \\
\hline $\begin{array}{l}\text { Q25e: interest in making scientific } \\
\text { observations }\end{array}$ & 0.864 & & 0.223 \\
\hline $\begin{array}{l}\text { Q26a: confidence to design an experiment } \\
\text { to answer a scientific question }\end{array}$ & & 0.850 & 0.336 \\
\hline $\begin{array}{l}\text { Q26b: confidence to conduct an } \\
\text { experiment on your own }\end{array}$ & & 0.896 & 0.325 \\
\hline $\begin{array}{l}\text { Q26c: confidence to interpret experimental } \\
\text { results }\end{array}$ & & 0.869 & 0.336 \\
\hline $\begin{array}{l}\text { Q26d: confidence to write a lab } \\
\text { report/scientific paper }\end{array}$ & & 0.822 & 0.259 \\
\hline $\begin{array}{l}\text { Q26e: confidence to apply science } \\
\text { knowledge to an assignment or test }\end{array}$ & & 0.721 & 0.284 \\
\hline $\begin{array}{l}\text { Q26f: confidence to explain a science topic } \\
\text { to someone else }\end{array}$ & & & 0.555 \\
\hline $\begin{array}{l}\text { Q26g: confidence to get good grades in } \\
\text { science }\end{array}$ & & & \\
\hline
\end{tabular}


The 9 items for agency and being critical did not align as expected on the theorized subconstructs. Namely, the theorized construct of being critical did not load separately from the questions constructed to measure agency. Instead, the questions loaded as questions that related directly to students' lives and included first-person personal and possessive pronouns, such as "I”, “me”, and “my”. The other factor included questions about how students viewed the ability of science to change the world. Factor loadings ranged from 0.543 to 0.957 indicating that, to a great extent, items accurately captured the same construct. The mean loading for personal agency was 0.831 ,and the mean loading for global agency was 0.738 . It is important to note that the global agency construct identified here is a true agency measure because all of the students in this analysis have already indicated they intend on a STEM career. If this were not the case, the view of science's potential to affect the world may not be agential in character. Students' beliefs about science's impact on their lives coupled with a choice of STEM implies that these students see STEM as a way to accomplish change in their world, and, therefore, hold agential beliefs about science in a personal and/or global sense.

Table 4: EFA of Agency Constructs

\begin{tabular}{|l|c|c|c|}
\hline \multicolumn{1}{|c|}{ Statement } & $\begin{array}{c}\text { Factor 1 - } \\
\text { Personal Agency }\end{array}$ & $\begin{array}{c}\text { Factor 2- } \\
\text { Global Agency }\end{array}$ & Uniqueness \\
\hline $\begin{array}{l}\text { Q29a: learning science will improve my } \\
\text { career prospects }\end{array}$ & 0.795 & & 0.335 \\
\hline $\begin{array}{l}\text { Q29b: science is helpful in my everyday } \\
\text { life }\end{array}$ & 0.933 & & 0.196 \\
\hline $\begin{array}{l}\text { Q29c: science has helped me see } \\
\text { opportunities for positive change }\end{array}$ & 0.957 & & 0.149 \\
\hline $\begin{array}{l}\text { Q29d: science has taught me how to take } \\
\text { care of my health }\end{array}$ & 0.721 & & 0.350 \\
\hline $\begin{array}{l}\text { Q29e: leaning science has made me more } \\
\text { critical in general }\end{array}$ & 0.749 & & 0.337 \\
\hline $\begin{array}{l}\text { Q29f: science and technologies will } \\
\text { provide greater opportunities for future } \\
\text { generations }\end{array}$ & & & 0.543 \\
\hline $\begin{array}{l}\text { Q29j: a country needs science and } \\
\text { technology to become developed }\end{array}$ & & 0.738 & 0.472 \\
\hline $\begin{array}{l}\text { Q29m: science and technology make our } \\
\text { lives healthier, easier and more } \\
\text { comfortable }\end{array}$ & & 0.899 & 0.265 \\
\hline $\begin{array}{l}\text { Q29n: the benefits of new technologies } \\
\text { greatly outweigh the risks }\end{array}$ & & 0.772 & 0.483 \\
\hline
\end{tabular}

After the the questions for each identity sub-construct were verified, the composite constructs of math identity, physics identity, and general science identity were created by averaging the subconstructs for a single overall measure. Additionally, the questions for personal agency and global agency were averaged into two overall constructs for agency. These three identity 
constructs and two agency constructs were regressed on the choice of engineering and the choice of science in college. Gender, father's education, and mother's education were used as controls in the regression. Parent's education was used as a proxy for socio-economic status, which has been found previously to be a strong predictor of SES. ${ }^{19}$ Results from the regression model predicting the choice of engineering as a career, appear in Table 5. The results for the regression model predicting a choice of science as a career (physicist, chemist, biologist, environmental scientist, etc.) are included in Table 6. These regression models show that the constructs used in this analysis are strongly predictive of the choice of engineering or science, with a few notable differences. For students who choose engineering, the estimate for male parental guardian's education level is a significant negative predictor for the choice of engineering $(p<0.01)$. Previous literature has shown that the socio-economic status of students who choose engineering is lower than students who choose science. ${ }^{19}$ Thus, the difference seen on this factor between science and engineering students is not surprising. Female parental guardian education level is non-significant for both engineers and scientists. Being female is a negative predictor for choice of engineering $(p<0.001)$ and a positive predictor for choice of a science career $(p<0.001)$. This difference is seen in the gender control variable because engineering is an underrepresented field while science has reached parity in gender representation as a whole. ${ }^{20}$ One major difference seen between engineering and science students is a strong connection between mathematics identity $(\mathrm{p}<0.001)$ and engineering career choice, which is non-significant for a science career choice. Science students and engineering students both show strong personal agency in their views of science's ability to affect their immediate world $(\mathrm{p}<0.001)$. However, there is a marked difference in the way that science and engineering students view science's ability to affect the larger world, or what we have termed global agency. The global agency factor is a significant negative predictor for science students $(\mathrm{p}<0.001)$ but is non-significant for engineering students.

Table 5: Regression on choice of engineering $\left(\mathrm{N}=2501\right.$, Adjusted $\left.\mathrm{R}^{2}=0.295\right)$.

\begin{tabular}{|l|c|c|c|c|}
\hline \multicolumn{1}{|c|}{ Factor } & Estimate & Std. Error & Beta Coefficient & Significance $^{\S}$ \\
\hline Gender (0-male; 1-female) & -0.703 & 0.052 & -0.237 & $* * *$ \\
\hline Father's Education & -0.076 & 0.025 & -0.0641 & $* *$ \\
\hline Mother's Education & -0.004 & 0.027 & -0.0033 & $\mathrm{n} / \mathrm{s}$ \\
\hline Math Identity & 0.152 & 0.023 & 0.1285 & $* * *$ \\
\hline Physics Identity & 0.259 & 0.027 & 0.2085 & $* * *$ \\
\hline Science Identity & 0.33 & 0.056 & 0.1476 & $* * *$ \\
\hline Personal Agency & 0.139 & 0.036 & 0.1022 & $* * *$ \\
\hline Global Agency & -0.056 & 0.035 & -0.03495 & $\mathrm{n} / \mathrm{s}$ \\
\hline
\end{tabular}

$\S$ The level of statistical significance is coded in the final column: $\mathrm{n} / \mathrm{s}$ represents a non-significant result, * represents a statistical significance less than 0.05 but greater than or equal to $0.01,{ }^{* *}$ represents a statistical significance less than 0.01 but greater than or equal to 0.001 , and ${ }^{* * *}$ represents a statistical significance less than 0.001 . 
Table 6: Regression on choice of science $\left(\mathrm{N}=2530\right.$, Adjusted $\left.\mathrm{R}^{2}=0.334\right)$.

\begin{tabular}{|l|c|c|c|c|}
\hline \multicolumn{1}{|c|}{ Factors } & Estimate & Std. Error & Beta Coefficient & Significance $^{\S}$ \\
\hline Gender (0-male; 1-female) & 0.271 & 0.049 & 0.092 & $* * *$ \\
\hline Father's Education & -0.029 & 0.024 & -0.0248 & $\mathrm{n} / \mathrm{s}$ \\
\hline Mother's Education & -0.004 & 0.026 & -0.00303 & $\mathrm{n} / \mathrm{s}$ \\
\hline Math Identity & 0.02 & 0.022 & 0.01756 & $\mathrm{n} / \mathrm{s}$ \\
\hline Physics Identity & 0.151 & 0.026 & 0.12359 & $* * *$ \\
\hline Science Identity & 0.624 & 0.053 & 0.28317 & $* * *$ \\
\hline Personal Agency & 0.43 & 0.0347 & 0.32101 & $* * *$ \\
\hline Global Agency & -0.143 & 0.0337 & -0.0905 & $* * *$ \\
\hline
\end{tabular}

\section{Discussion}

The regression models show that there are differences in science and engineering students on a few factors. Math, physics, and science identities along with strong beliefs about science's role in their personal lives (personal agency) contribute significantly to a choice of engineering. These attitudes explain a large portion of the variance in the choice of engineering (0.295). While these constructs can account for some of the reasons students choose engineering, other factors like career expectations and other agential pieces about engineering may explain a larger portion. Future work should be conducted to understand more of these influencing factors on the choice of engineering in building a model of engineering career choice for high school students. Similarly, students who chose science majors in college had significantly positive physics and general science identities along with personal agency, but the construct of global agency was actually a negative predictor for the choice of science in college.

One possible reason for this difference in global agency is that students perceive differences in the communities of practice of scientists and engineers. Scientists may solve problems similarly to engineers, but their goal is usually to explain, model or understand how the world works around them. Engineers, on the other hand, may solve problems with a pragmatic picture in mind. Their perceived value of discovery and information is encoded in the systems they build rather than in scientific laws or facts. ${ }^{21}$ Engineering students frequently solve large systems with the "big picture" in mind. Many young students in science deal with small-scale, detailed experiments and may not be able to translate their findings into a solution with far-reaching implications. Or, these science students may be more skeptical of what science can do for the world than their engineering peers. These ideas may explain our measurement that engineering students have a high degree of personal agency and higher global agency than science students while science students only exhibit a strong personal agency.

Math and physics identity constructs have been used to predict the choice of a math or physics career. ${ }^{15,16}$ When these constructs were applied to engineering, the physics construct seemed too restrictive to predict an engineering career for a variety of engineering disciplines. Engineering students may not all have a strong physics identity; for example, students in engineering disciplines that involve chemistry and biological processes may not necessarily have a strong 
affinity towards physics. With this hypothesis in mind, general science identity factors were also measured with the same theoretical foundation as the published math and science identities.

While the recognition sub-construct was not well measured by the questions in the SaGE survey, the interest and performance/competency pieces were captured, and this construct was included in the regression models to model interest in science besides physics.

These results are a step toward understanding why students may choose engineering over science. Students who choose a career in engineering may base their decision on their ability in math and science along with other factors. The framework of critical engineering agency may provide a way to understand why students choose engineering specifically. As a first step toward quantitatively measuring and validating this framework, the identity and agency constructs were built using exploratory factor analysis. This analysis showed that several items appropriately measure the three factors for mathematics and physics identity as theorized. Additionally, this process allowed for the identification and removal of items that did not accurately measure these sub-constructs. When general science identity construct was included, the questions theorized to measure recognition did not load into a single factor and were removed from the analysis.

Future work to validate this newer measure will include developing items that measure students' perceptions of recognition in science generally.

\section{Conclusion}

In the analyses reported in this paper, constructs have been developed for measuring critical engineering agency quantitatively. Some aspects of identity have been captured by math and science factors (physics as well as general science). The aspects of being a critic and having agency did not load on two separate factors as expected. Instead, the questions grouped differently into two factors based on the immediacy of the perceived influence of science in students' lives. These two new factors were termed personal and global agency based on the observed differentiation of the factors. Through this analysis it was found that engineering students have a strong personal agency and that global agency has no significant relationship on the choice of engineering. Conversely, having a strong global agency was a negative predictor for a science career. Since many students who choose science have strong science identities and strong math skills (as engineering students do as well), this factor may be used to differentiate between students who choose science and engineering careers. This finding has implications for recruitment, retention, and pedagogy for engineering students. If the previously uninformed and possibly irrational decision of an engineering career can be understood through these constructs, more students can be identified, encouraged, and developed to become engineers.

This work reaffirms the importance of experiences and attitudes towards mathematics and science to future engineering students but it also illustrates the differences in students beliefs about the impact of these subjects on their future career choices. Furthermore, this examination revealed that the differences between students who choose engineering over science are significant for some of the factors considered in this paper, particularly math identity and global agency.

Providing some validation of these constructs is a first step in building a predictive model for the choice of engineering. Understanding why students choose engineering in particular, out of the 
spectrum of STEM disciplines, can assist in identifying students who would not normally choose engineering for recruitment and developing pedagogy to retain these students in engineering. Both of these scenarios are an opportunity to increase the number of engineers and engineering solutions for the future.

\section{Bibliography}

(1) Presidents' Council of Advisors on Science and Technology. Engage to Excel: Producing One Million Additional College Graduates with Degrees in Science, Technology, Engineering, and Mathematics; 2012; p. 130.

(2) Basu, S. J.; Barton, A. C.; Clairmont, N.; Locke, D. Developing a Framwork for Critical Science Agency Through a Case Study in a Conceptual Physics Context. Cultural Studies of Science Education. 2008, 4, 373-378.

(3) Basu, S. J.; Barton, A. C. Critical Physics Agency: Further Unraveling the Intersections of Subject Matter Knowledge. Cultural Studies of Science Education. 2009, 4, 387-392.

(4) Basu, S. J.; Barton, A. C. A Researcher-Student-Teacher Model for Democratic Science Pedagogy: Connections to Community, Shared Authority, and Critical Science Agency. Equity \& Excellence in Education 2010, 431, 72-87.

(5) Miller, J. A. The Science and Engineering Workforce: Realizing America's Potential.; 2003.

(6) Johnson, A.; Brown, J.; Carlone, H.; Cuevas, A. Authoring Identity Amid the Treacherous Terrain of Science: A Multiracial Feminist Examination of the Journeys of Three Women of Color in Science. Journal of Research in Science Teaching. 2011, 48, 339-366.

(7) Brickhouse, N. W.; Lowery, P.; Schultz, K. What Kind of a Girl Does Science? The Construction of School Science Identities. Journal of Research in Science Teaching. 2000, 37, 441-458.

(8) Godfrey, E.; Parker, L. Mapping the cultural landscape in engineering education. Journal of Engineering Education. 2010, 99, 5-22.

(9) Matusovich, H.; Streveler, R.; Miller, R. Why do students choose engineering? A qualitative, longitudinal investigation of students' motivational values. Journal of Engineering Education 2010, 99, 289-304.

(10) Chachra, D.; Kilgore, D.; Loshbaugh, H.; McCain, J.; Chen, H. Being and becoming: gender and identity formation of engineering students. In American Society of Engineering Education Conference; 2008.

(11) Tonso, K. L. Student Engineers and Engineer Identity: Campus Engineer Identities as Figured World. Cultural Studies of Science Education. 2006, 1, 273-307.

(12) Capobioanco, B. M.; French, B. F.; Diefes-Dux, H. A. Engineering Identity Development Among PreAdolescent Learners. Journal of Engineering Education 2012, 101, 698-716.

(13) Matusovich, H. M.; Barry, B. E.; Meyers, K.; Louis, R. A Multi-Institution Comparison of Identity Development as an Engineer. In American Society of Engineering Education Conference; 2011.

(14) Beam, T. K.; Pierrakos, O.; Constantz, J.; Johri, A.; Anderson, R. Preliminary Findings on Freshmen Engineering Students ’ Professional Identity : Implications for Recruitment and Retention. In American Society of Engineering Education Conference; 2009.

(15) Hazari, Z.; Sonnert, G.; Sadler, P. M.; Shanahan, M.-C. Connecting high school physics experiences, outcome expectations, physics identity, and physics career choice: A gender study. Journal of Research in Science Teaching. 2010, 47, 978-1003.

(16) Cass, C. A.; Hazari, Z.; Cribbs, J.; Sadler, P. M.; Sonnert, G. Examining the Impact of Mathematics Identity on the Choice of Engineering Careers for Male and Female Students. In Frontiers in Education Conference (FIE); 2011; p. F2H-1. 
(17) Carlone, H. B.; Johnson, A. Understanding the Science Experiences of Successful Women of Color : Science Identity as an Analytic Lens. Journal of Research in Science Teaching 2007, 44, 1187-1218.

(18) The Core Development Team. R: A language and environment for statistical computing 2012.

(19) Potvin, G.; Tai, R.; Sadler, P. The Difference Between Engineering and Science Students: Comparing Backgrounds and High School Experiences. In American Society of Engineering Education Conference; 2009; p. 14.

(20) National Council of Education Statistics. Digest of Education Statistics http://nces.ed.gov/Programs/digest/ (accessed Mar 3, 2012).

(21) Kennedy, J. M.; Pinelli, T. E.; Barclay, R. O.; Bishop, A. P. Distinguishing engineers from scientists- the case for an engineering knowledge community.; Ablex Publishing Corp.: Greenwhich, CT, 1997; pp. 177-213. 